\title{
Cost-effectiveness analysis of ranibizumab for retinal vein occlusion patients in China from the societal perspective
}

Weiyi $\mathrm{Ni}^{1}$, Jia Liu ${ }^{2,3}$, Yawen Jiang ${ }^{4}$ and Jing $\mathrm{Wu}^{2,3^{*}}$

\begin{abstract}
Background: Clinical trials in China have demonstrated that ranibizumab can improve the clinical outcomes of branch retinal vein occlusion (BRVO) and central retinal vein occlusion (CRVO). However, no economic evaluation of ranibizumab has been conducted among Chinese patient population.

Methods: To provide insights into the economic profile of ranibizumab among Chinese RVO population, a Markov state-transition model was used to predict the outcomes of ranibizumab comparing to laser photocoagulation and observational-only care from the societal perspective. This model simulated changes in patient visuality, qualityadjusted of life years (QALY), medical costs, and direct non-medical costs of individuals with visual impairment due to BRVO or CRVO in lifetime. The base-case analysis used an annual discount rate of 5\% for costs and benefits following the China Guidelines for Pharmacoeconomic Evaluations. Deterministic and probabilistic sensitivity analyses were performed to test the robustness of the model.
\end{abstract}

Results: The base-case incremental cost-effectiveness ratio (ICER) comparing ranibizumab to laser photocoagulation was $¥ 65,008$ /QALY among BRVO patients and was $¥ 65,815$ /QALY among CRVO patients, respectively. Comparing to the 2019 gross domestic product (GDP) per capita of $¥ 71,000$, both two ICERs were far below the cost-effective threshold at three times of GDP per capita $(¥ 213,000)$. The deterministic and probabilistic sensitivity analyses demonstrated the base-case results were robust in most of the simulation scenarios.

Conclusion: The current Markov model demonstrated that ranibizumab may be cost-effective compared with laser photocoagulation to treat BRVO and cost-effective compared to observation-only care to treat CRVO in China from the societal perspective.

Keywords: Ranibizumab, BRVO, CRVO, Cost-effectiveness

\section{Background}

Retinal vein occlusion (RVO), including the central retinal vein occlusion (CRVO) and branch retinal vein occlusion (BRVO), is a prevalent vision-threatening disease. The International Eye Disease Consortium reported that the prevalence of RVO in the USA, Europe,

\footnotetext{
* Correspondence: jingwu@tju.edu.cn

${ }^{2}$ School of Pharmaceutical Science and Technology, Tianjin University, Nankai District, Room 209, 24th building, 92th Weijin Road, Tianjin 300072, China ${ }^{3}$ Center for Social Science Survey and Data, Tianjin University, Tianjin, China Full list of author information is available at the end of the article
}

Asia, and Australia was $0.52 \%$ for any RVO, $0.44 \%$ for BRVO, and $0.08 \%$ for CRVO [1].

Macular edema (ME) is a common visual complication and a primary cause of visual loss in patients with RVOs. ME secondary to BRVO is generally treated with laser photocoagulation or anti-vascular endothelial growth factor (VEGF) agents. Clinical trials have shown that anti-VEGF therapies are more effective at improving best-corrected visual acuity (BCVA) than laser photocoagulation [2]. More, although anti-VEGF therapy has

C C The Author(s). 2021 Open Access This article is licensed under a Creative Commons Attribution 4.0 International License, which permits use, sharing, adaptation, distribution and reproduction in any medium or format, as long as you give appropriate credit to the original author(s) and the source, provide a link to the Creative Commons licence, and indicate if changes were made. The images or other third party material in this article are included in the article's Creative Commons licence, unless indicated otherwise in a credit line to the material. If material is not included in the article's Creative Commons licence and your intended use is not permitted by statutory regulation or exceeds the permitted use, you will need to obtain permission directly from the copyright holder. To view a copy of this licence, visit http://creativecommons.org/licenses/by/4.0/ The Creative Commons Public Domain Dedication waiver (http://creativecommons.org/publicdomain/zero/1.0/) applies to the data made available in this article, unless otherwise stated in a credit line to the data. 
better clinical efficacy, observation-only care is still a common treatment for CRVO, especially among newly diagnosed patients [3-5].

Laser photocoagulation used to be the standard care for $\mathrm{ME}[3,6]$. However, in cases of severe ME, retinal swelling may reduce the penetration power of laser, leading to poor treatment effects, which is a major drawback of laser photocoagulation. Although anti-VEGF agents are shown to be more beneficial in treating RVO patients through clinical trials, the treatment itself requires multiple repeat intravitreal injections to maintain the clinical outcomes. Consequently, it is likely to incur higher medication expenditure of the healthcare system.

Recently, BLOSSOM and CAMELLIA clinical trials in China have demonstrated that ranibizumab is more effective than observation-only care for BRVO and CRVO $[7,8]$. Hence, the introduction of ranibizumab into the Chinese healthcare system may represent an opportunity to improve the health outcomes of RVO patients in China. However, its incremental clinical effectiveness still has to be weighed against higher acquisition expenditure, including the cost of ranibizumab and administration charge. Although studies in Europe demonstrated that ranibizumab is cost-effective comparing to laser photocoagulation and observation-only care, the conclusion may not be portable to the Chinese healthcare system because costs of medical services, medical resource utilization and productivity loss can vary substantially across the two regions. To provide insights into the economic profile of ranibizumab among Chinese RVO population, the current study used a Markov decision model to predict the outcomes of ranibizumab comparing to laser photocoagulation and observational-only care from the societal perspective.

\section{Methods}

\section{Model structure}

A Markov model was adapted to simulate both Chinese BRVO and CRVO patient population using Microsoft Excel from the societal perspective. The model was reported in a previous study [9], containing eight BCVA health states defined using the Early Treatment Diabetic Retinopathy Study (ETDRS) letter scale and an absorbing state of death. Within the monthly cycle, each individual can move among different status (Fig. 1).

This model simulated changes in BCVA, qualityadjusted of life years (QALY), medical costs and direct non-medical costs of individuals with visual impairment due to BRVO or CRVO in lifetime. The starting age of BRVO population was 57 years and the starting age of CRVO patients was 54 year, which were the mean age years of patient population of corresponding pivotal clinical trials in China. The base-case analysis used an annual discount rate of $5 \%$ for costs and benefits following the China Guidelines for Pharmacoeconomic Evaluations. All costs were inflated to 2019 Chinese Yuan.

\section{Clinical input}

The model's clinical inputs in year 1 were obtained from the BLOSSOM and CAMILLIA trials (Table 1). Monthly transition probabilities were observed and calculated for each treatment arm, respectively. For the transition probabilities of the ranibizumab treatment arm, data from the $0.5 \mathrm{mg}$ arm in BLOSSOM and CAMILLIA up to 12 months were observed. Similarly, transition probabilities for laser photocoagulation among BRVO patients were calculated using data from the control group of BLOSSOM trial for the first 12 months and the relative risk of laser photocoagulation to the observational-

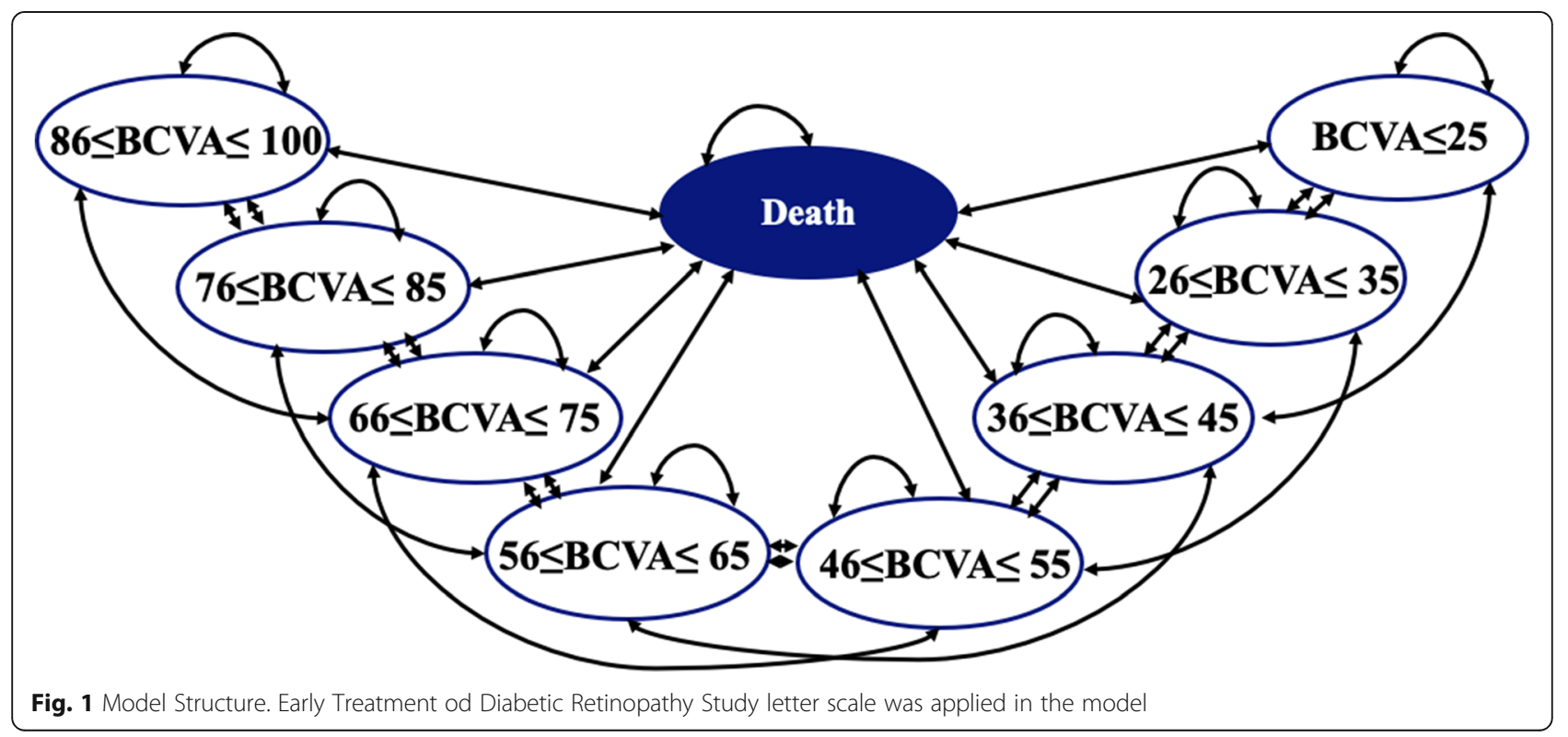


Table 1 Model input for effectiveness data

\begin{tabular}{|c|c|c|c|c|}
\hline & \multicolumn{2}{|l|}{ BRVO } & \multicolumn{2}{|l|}{ CRVO } \\
\hline & Ranibizumab & Laser Photocoagulation & Ranibizumab & Observation \\
\hline Month 1 & BLOSSOM & BLOSSOM & CAMELLIA & CAMELLIA \\
\hline Month 2-6 & BLOSSOM & BLOSSOM & CAMELLIA & CAMELLIA \\
\hline Months 7-12 & BLOSSOM & BLOSSOM & CAMELLIA & CAMELLIA \\
\hline Year 2 & Horizon & Horizon & Horizon & Horizon \\
\hline Year 3 & Natural History & Natural History & Natural History & Natural History \\
\hline
\end{tabular}

only care from a 2015 study [10]; thereafter, patients using laser photocoagulation treatment were assumed to follow the same transition probabilities as ranibizumab. For the observation-only group in CRVO model setting, transition probabilities were estimated using the control arm of CAMELLIA for the first 12 months. Assuming patients achieved stability at the end of year 2 except for the decrease in BCVA score because of the natural aging effect, ranibizumab effectiveness data in year 2 were taken as the transition probability at Month 12 . Deterioration in BCVA since year 3 was from a population based observational study [11].

The economic model tracked patients' health status based on their BCVA scores in the treated eye, which could be either the better-seeing eye (BSE) or the worseseeing eye (WSE). The starting distribution of BCVA levels were obtained from two BLOSSOM and CAME LLIA trials in China (Additional file 1: Table 1. More, according to the proportions of patients in the trials, the model assumed that $10 \%$ of patients whose BSE was treated at the beginning and the percentage raised to $21.5 \%$ at 12 months. The tariff scores used in the calculation of QALYs also varied depending on whether the BSE or the WSE was being treated. The model applied a weighted approach based on the number of patients whose BSE or WSE were treated.

\section{Utilities}

Health related quality-of-life of patients with visual impairment is primarily associated with the BCVA score of their BSE. Utility scores of patients whose affected eye is their BSE eye are normally lower in patients whose affected eye is their WSE. However, utility gains from improving BCVA are generally considered to be higher among patients treated in their BSE eye than in those treated in the WSE. Thus, it was important to apply the corresponding utilities that were specific to BSE or WSE, respectively [12]. Utilities from BSE associated with BCVA letter scores were determined based on the algorithm developed by Czoski-Murray et al. [13] and were used as the base-case in the current model. In the absence of utility data for the WSE, patients were assumed to experience a maximum gain in utility of 0.30 between the best and worst possible health states [9] (Table 2).

\section{Mortality}

All-cause mortality from the life table for China was applied [14]. The relationship between BCVA scores and the relative risk to all-cause mortality had been demonstrated in previous studies $[11,15,16]$. When the BSE was the affected eye, the risk ratio (RR) was applied to the BCVA levels including less than or equal 35 letters, 36 - 55 letters and more than 55 letters. The RRs were $1.54,1,23$ and 1.00, respectively. When the WSE was affected, a RR of 1.23 was applied to all BCVA levels that were less than or equal to 35 letters and a RR of 1.00 was applied to the other BCVA levels.

\section{Resource use}

Data on the frequency of ranibizumab treatment were collected from the BLOSSOM and CAMELLIA trails. Physicians from the 6 hospitals were interviewed on the treatment pattern of laser photocoagulation and observation-only care, follow-up visits and other medical services for RVO up to 5 years after the first admission (Table 3). The follow-up visits for BRVO patients could last for 5 years, while the follow-up visits for CRVO lasted for 3 years with a decreasing pattern.

\section{Costs}

Unit costs of direct medical services were also obtained from the same survey, including the costs of ranibizumab, laser photocoagulation treatment, observation-only

Table 2 Utility Scores by BCVA Level

\begin{tabular}{lcc}
\hline BCVA level & BSE utility & WSE utility \\
\hline $86-100$ & 0.85 & 0.85 \\
$76-85$ & 0.76 & 0.84 \\
$66-75$ & 0.69 & 0.82 \\
$56-65$ & 0.61 & 0.81 \\
$46-55$ & 0.54 & 0.79 \\
$36-45$ & 0.46 & 0.78 \\
$26-35$ & 0.39 & 0.75 \\
$<25$ & 0.35 & 0.75 \\
\hline
\end{tabular}


Table 3 Frequency of healthcare resource use

\begin{tabular}{|c|c|c|c|c|}
\hline & \multicolumn{2}{|l|}{ BRVO } & \multicolumn{2}{|l|}{ CRVO } \\
\hline & Ranibizumab & Laser Photocoagulation & Ranibizumab & Observation \\
\hline \multicolumn{5}{|l|}{ Treatment visits } \\
\hline First Year & 7.0 & 1.4 & 8.2 & 0 \\
\hline Second Year & 2.1 & 0.3 & 3.5 & 0 \\
\hline \multicolumn{5}{|l|}{ Follow-up visits } \\
\hline First Year & 2.3 & 4.9 & 2 & 5.4 \\
\hline Second Year & 0.8 & 1.8 & 1.4 & 3 \\
\hline Third Year & 1.1 & 1 & 0.8 & 1.3 \\
\hline Fourth Year & 0.6 & 0.8 & 0.3 & 0.8 \\
\hline Fifth Year & 0.2 & 0.2 & 0.3 & 0.3 \\
\hline
\end{tabular}

care, and follow-up visits (Table 4). A study in China demonstrated that the long-term annual non-medical costs and indirect medical costs were associated with BCVA levels [17]. When the BCVA score of the BSE was less than or equal to 35 , the annual costs were $¥ 47,396$ and when the score were between 36 and 55 letters, the costs were $¥ 30,849$. With BCVA letters greater than 55 , no additional non-medical or indirect medical costs were applied.

\section{Productivity loss}

Poor visuality caused by RVO may possibly lead to productivity loss of patients and requires additional care from family members or caregivers. As the present analysis was conducted from the societal perspective, the productivity loss of patients or caregivers were also taken into account. Similar to the resource use and costs data, the days of productivity loss on Chinese BRVO and CRVO patient population were also obtained through a survey at hospitals. According to the interviewed physicians, the productivity loss varied by BCVA levels. For BRVO patients in the health states of 26 BCVA letters and better, the average productivity loss from caregivers was 9.5 days per year. The corresponding number was 11.75 days for health states worse than 26 BCVA letters.

Table 4 Costs of healthcare services

\begin{tabular}{lr}
\hline Item & Unit costs \\
\hline Drug & \\
Ranibizumab (unit costs) & $¥ 3,950.00$ \\
Medical treatment services & \\
Laser & $¥ 605.00$ \\
Administration of ranibizumab & $¥ 776.00$ \\
Follow-up visit & $¥ 664.00$ \\
Annual indirect medical costs and non-medical service & \\
BCVA 36-55 & $¥ 30,849.00$ \\
BCVA $<=35$ & $¥ 47,396.00$ \\
\hline
\end{tabular}

The average productivity loss for BRVO patients associated with the two health states was 13.25 and 365.25 days per year, respectively. The average productivity loss from caregivers for CRVO patients were 13.25 days per year for all levels of BCVA. The productivity loss was 13.25 days per year for CRVO patients themselves when their BCVA were greater than 26 letters and better and were 365.25 when less than 26 letters. The total costs of productivity loss were calculated as the days of productivity loss multiplying the productivity per day per capita. Base on the GDP per capita in China 2019, the productivity per capita per day were $¥ 194$.

\section{Sensitivity analysis}

One-way deterministic sensitivity analyses were performed to evaluate the robustness of the model in the presence of uncertainty of key parameter values. Additionally, a probabilistic sensitivity analysis (PSA) was also conducted, the distributions of key input parameters in which are listed in Table 5. Beta-distributions were used for transition probabilities while gamma distributions were used for costs. Normal distributions were used for age and utility. The log-normal distributions were used for risk ratios. Each model was simulated for 5,000 times to generate an acceptance curve.

The study protocol is performed in accordance with the relevant guidelines.

\section{Results}

Treating BRVO with ranibizumab was shown to produce an increase of 0.646 QALY with incremental costs of $¥ 42,027$ compared to laser photocoagulation over a lifetime horizon from the societal perspective. The incremental cost-effectiveness ratio (ICER) was ¥65,008/ QALY, which was slightly lower than once the 2019 gross domestic product (GDP) per capita (highly costeffective threshold, $¥ 71,000$ ) and far below the three times the 2019 GDP per capita (cost-effective threshold, $¥ 213,000)$ in China. The CRVO patients using 
Table 5 Parameter values for probabilistic sensitivity analysis

\begin{tabular}{|c|c|c|c|c|c|}
\hline & Mean & Variation & Distribution & $a$ & $\beta$ \\
\hline \multicolumn{6}{|l|}{ General } \\
\hline Starting age & 54 & 5 & Normal & $\mathrm{n} / \mathrm{a}$ & $\mathrm{n} / \mathrm{a}$ \\
\hline$\%$ BSE at baseline & 0.1 & $\mathrm{n} / \mathrm{a}$ & Beta & 52.2 & 469.8 \\
\hline \multicolumn{6}{|l|}{ Quality of life } \\
\hline Tx effectiveness probs-month 1 & 1 & 0.1 & Lognormal & $\mathrm{n} / \mathrm{a}$ & $\mathrm{n} / \mathrm{a}$ \\
\hline Tx effectiveness probs-month 2 to 6 & 1 & 0.1 & Lognormal & $\mathrm{n} / \mathrm{a}$ & $\mathrm{n} / \mathrm{a}$ \\
\hline Tx effectiveness probs - month 7 to 12 & 1 & 0.1 & Lognormal & $\mathrm{n} / \mathrm{a}$ & $\mathrm{n} / \mathrm{a}$ \\
\hline Comp effectiveness probs-month 1 & 1 & 0.1 & Lognormal & $\mathrm{n} / \mathrm{a}$ & $\mathrm{n} / \mathrm{a}$ \\
\hline Comp effectiveness probs-month 2 to 6 & 1 & 0.1 & Lognormal & n/a & $\mathrm{n} / \mathrm{a}$ \\
\hline Comp effectiveness probs-month 7 to 12 & 1 & 0.1 & Lognormal & $\mathrm{n} / \mathrm{a}$ & $\mathrm{n} / \mathrm{a}$ \\
\hline Natural deterioration & 0.00031 & $\mathrm{n} / \mathrm{a}$ & Beta & 3.1 & 9996.9 \\
\hline \multicolumn{6}{|l|}{ Quality of life } \\
\hline Utilities (all) & 1 & 0.05 & Normal & n/a & $\mathrm{n} / \mathrm{a}$ \\
\hline \multicolumn{6}{|l|}{ Costs } \\
\hline Administration costs (all other treatments) & 1 & 0.2 & Gamma & 25 & 0.04 \\
\hline Follow up costs (all treatments) & 1 & 0.2 & Gamma & 25 & 0.04 \\
\hline Treatment visits year 1 (ranibizumab) BRVO & 7.0 & 0.7 & Gamma & 100 & 0.07 \\
\hline Treatment visits year 2 (ranibizumab) BRVO & 2.1 & 0.21 & Gamma & 100 & 0.021 \\
\hline Treatment visits year 1 (laser) & 1.4 & 0.14 & Gamma & 100 & 0.014 \\
\hline Treatment visits year 2 (laser) & 0.3 & 0.03 & Gamma & 100 & 0.003 \\
\hline Treatment visits year 1 (ranibizumab) CRVO & 8.2 & 0.82 & Gamma & 100 & 0.082 \\
\hline Treatment visits year 2 (ranibizumab) CRVO & 3.5 & 0.35 & Gamma & 100 & 0.035 \\
\hline
\end{tabular}

ranibizumab had a 0.551 QALY increase with an incremental cost of $¥ 36,244$, resulting in an ICER of $¥ 65,815$ / QALY. Similarly to BRVO, the ICER was slightly lower than highly cost-effective threshold and far below the cost-effective threshold (Table 6).

The results of the deterministic sensitivity analyses are displayed in Fig. 2. As illustrated, the BRVO model is most sensitive to the treatment effectiveness of ranibizumab between 7 and 12 months in the first year. When it was set to 0.7 -fold of the base-case value, the ICER reached $¥ 227,606$ per QALY, which is higher than the cost-effective threshold ( $¥ 213,000)$. The sensitivity analysis of CRVO model are most sensitive to the 712 month effectiveness probability of the observationonly care and the treatment effectiveness of ranibizumab between 2 and 6 months. The ICER could reach over $¥ 213,000$ when changing the value of the two parameters, indicating that ranibizumab could possibly be less cost-effective than observation-only care. The deterministic sensitivity analysis also demonstrated the ICERs could be affected through frequency of treatment, costs of treatment, and effectiveness probabilities in other treatment period besides 7-12 month. However, no changes in these parameters led to an ICER higher than $¥ 213,000$.

The acceptance curve of the BRVO model showed that the probability of ranibizumab being cost-effective is $55.8 \%$ with the willingness-to-pay per QALY at $¥ 71,000$. After adjusting the willingness-to-pay per QALY at $¥ 213,000$, the probability to favor ranibizumab increased to $86.5 \%$ (Fig. 3a). Meanwhile, the probability of ranibizumab to treat CRVO being cost-effective was $49.0 \%$ and $68.9 \%$ when the willingness-to-pay per QALY was $¥ 71,000$ and $¥ 213,000$, respectively (Fig. 3b).

Table 6 Base-case cost-effectiveness results

\begin{tabular}{|c|c|c|c|c|c|c|}
\hline & \multicolumn{3}{|l|}{ BRVO } & \multicolumn{3}{|l|}{ CRVO } \\
\hline & Ranibizumab & Laser Photocoagulation & $\overline{\text { Incremental }}$ & Ranibizumab & Observation & Incremental \\
\hline Total costs & $¥ 87,924$ & 45,952 & $¥ 41,971$ & $¥ 139,407$ & $¥ 103,163$ & $¥ 36,244$ \\
\hline QALYS & 8.954 & 8.309 & 0.646 & 9.480 & 8.929 & 0.551 \\
\hline Incremental cost per QALY & & & $¥ 65,008$ & & & $¥ 65,815$ \\
\hline
\end{tabular}




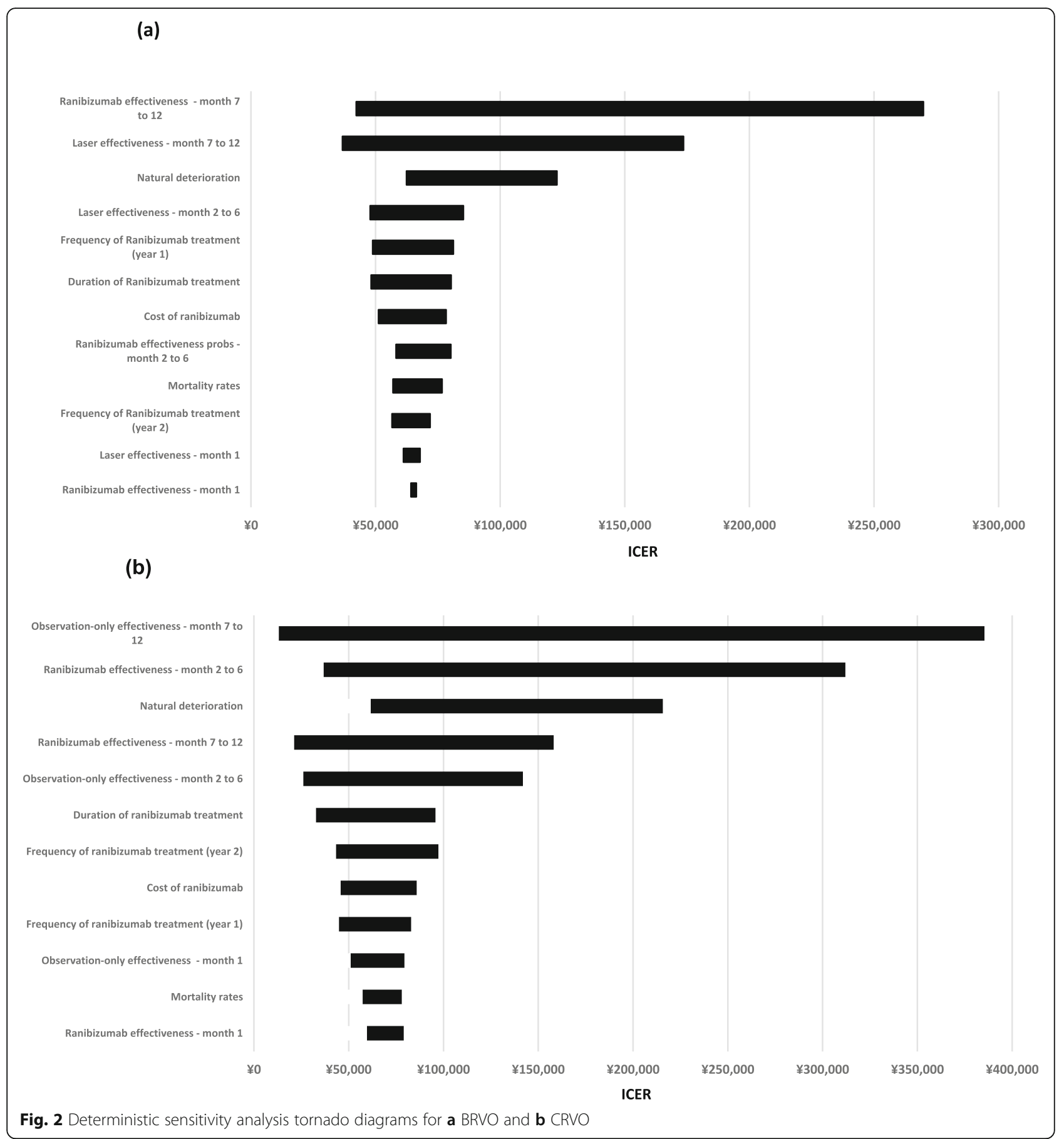

\section{Discussion}

The effectiveness inputs of the simulation model were mainly based on data derived from the BLOSSOM, CAMILLIA, and HORIZON (Cohort 2) clinical trials. The first two were designed and conducted for Chinese patient population. Thus, the data allowed a robust comparison of ranibizumab versus laser photocoagulation or observation-only care among RVO patients in China. The results demonstrated that ranibizumab was more cost-effective than laser photocoagulation for BRVO patients and confirmed that ranibizumab is also a costeffective treatment for CRVO patients comparing to observation-only care.

A key strength of the current study is the healthcare costs and resource utilization were specifically collected among Chinese patient population. The economic impact of ranibizumab on RVO has been conducted among the UK population [9], while the results cannot be 
(a)

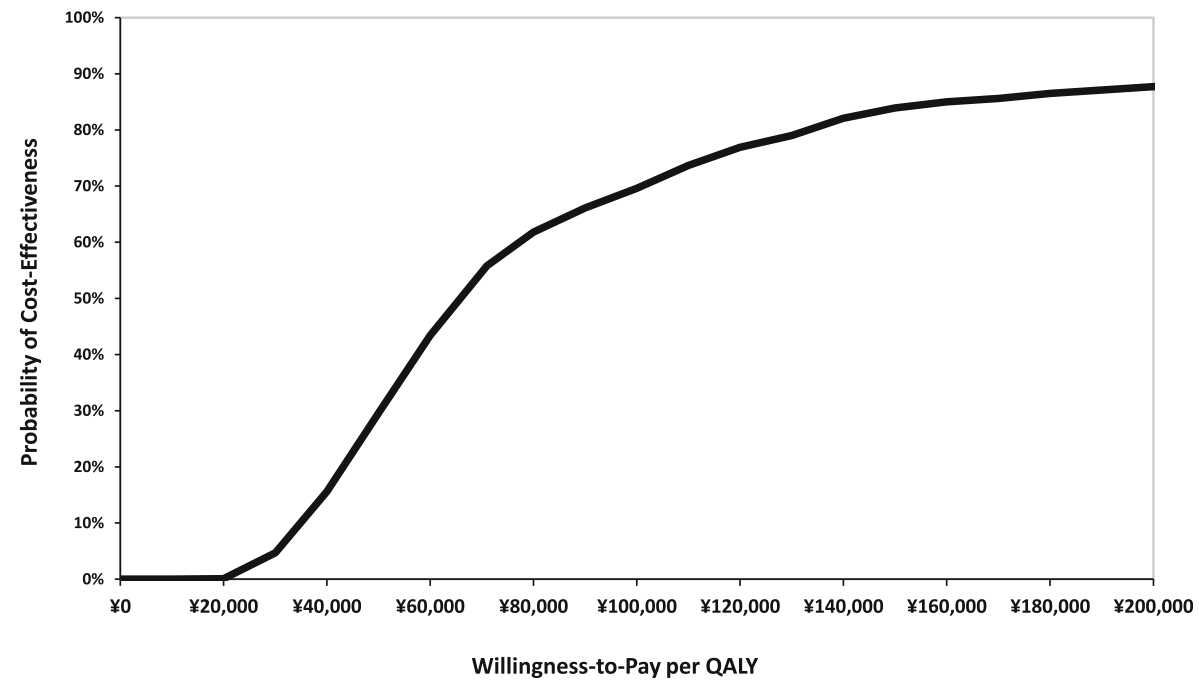

(b)

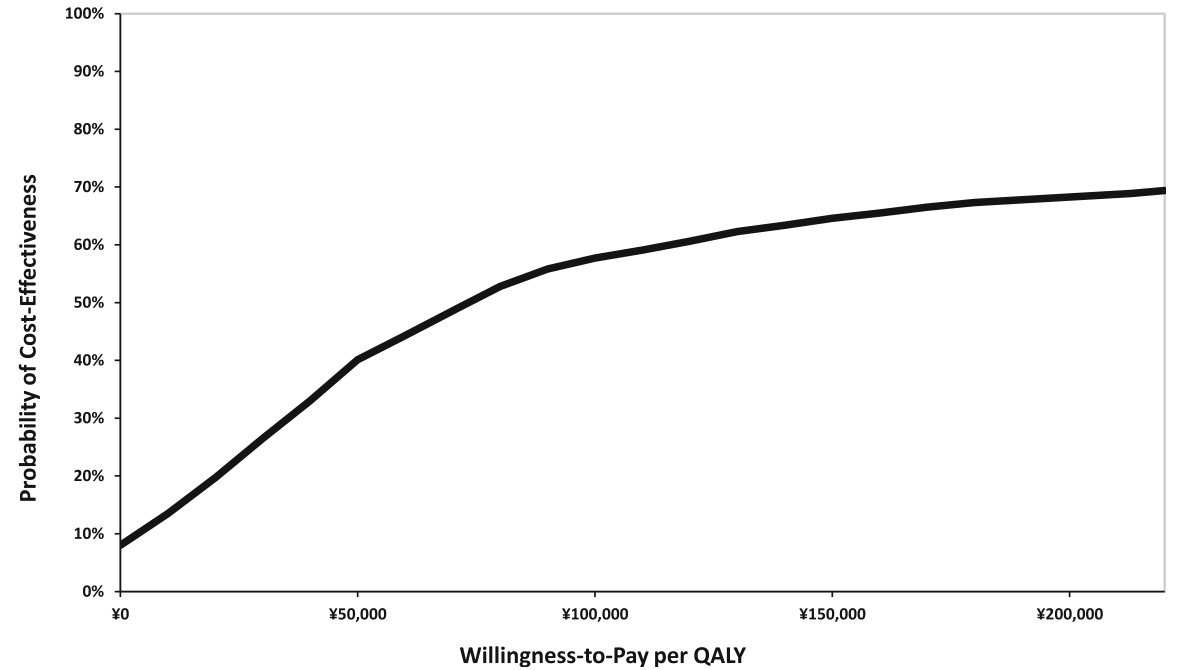

Fig. 3 Cost-effectiveness acceptability curves for a BRVO and $\mathbf{b}$ CRVO

simply applied as a reference for Chinese population because the healthcare care delivery system, unit cost of health services, and labor productivity are significantly different between the two regions. Thus, Chinesespecific inputs are essential for an accurate estimation of the cost-effectiveness profiles of alternative therapies. Because of the lack of the data in literature, we interviewed ophthalmologists from hospitals in 6 large cities across China to represent healthcare costs and resource utilization.

Another advantage is the current model covers not only the impact on healthcare costs but also the societal productivity loss. As RVO is highly possibly cause blindness, it may consequently lead to heavy societal burden through productivity loss. Similar as local healthcare costs, we collected productivity loss related to RVO through completing physician surveys, as no such data available from previous studies.

The current analysis is subject to several limitations. First, the input values of utility across BCVA levels were based on international studies rather than Chinesepopulation specified investigations. Health related utilities normally vary across populations. Hence, international utility values may possibly lead to biased 
results. To overcome this potential disadvantage, the impact of utility variation was tested through sensitivity analysis. Second, although the effectiveness data of ranibizumab on Chinese BRVO patients were extracted from the BLOSSOM trial, the comparable effectiveness of laser photocoagulation were not directly available in the same trial. Thus, if the effectiveness is available in future clinical trials, the model needs to be updated. Finally, the cost-effectiveness of the current model is sensitive to the choice of willingness-to-pay thresholds. Although 3 times the GDP per capita is commonly used as the threshold of WTP, once the GDP per capita is also widely accepted as the highly cost-effectiveness threshold.

\section{Conclusion}

The current Markov model demonstrated that ranibizumab is more likely cost-effective comparing with laser photocoagulation to treat BRVO and more likely costeffective comparing to observation-only care to treat CRVO from the societal perspective when the three times 2019 GDP per capita in China are applied as the willingness-to-pay per QALY.

\section{Abbreviations}

BCVA: Best-corrected visual acuity; BRVO: Branch retinal vein occlusion; BSE: Better-seeing eye; CRVO: Central retinal vein occlusion; ETDRS: Early treatment diabetic retinopathy study; GDP: Gross domestic product; ICER: Incremental cost-effectiveness ratio; ME: Macular edema; PSA: Probabilistic sensitivity analysis; QALY: Quality-adjusted of life years; VEGF: Vascular endothelial growth factor; WSE: Worse-seeing eye

\section{Supplementary Information}

The online version contains supplementary material available at https://doi. org/10.1186/s12886-021-01997-1

Additional file 1: Table 1. Distribution of baseline BCVA levels

\section{Acknowledgements}

Not Applicable

\section{Authors' contributions}

Participated in study design: WN, JL, YJ and JW. Conduct of the study: WN, $J L, Y J$ and JW. Performed data analysis: WN, JL and YJ. Wrote or contributed to the writing of the manuscript: WN, JL, YJ and JW. All authors have read and approved the final manuscript.

\section{Funding}

Not Applicable.

\section{Availability of data and materials}

The datasets analyzed in the current study are available from the corresponding author for reasonable requests.

\section{Declarations}

\section{Ethics approval and consent to participate}

The input parameters for this modeling study were obtained from published literature, expert opinion (the interview of the physicians from 6 hospitals), or generated from databases in which patient-identifiable information was not available. According to the opinion of the Ethics Committee of Tianjin
University, the need for ethics approval and consent to participate was waived for this study.

Consent for publication

Not Applicable.

\section{Competing interests}

The authors declare that they have no competing interests.

\section{Author details}

${ }^{1}$ Department of Pharmaceutical and Health Economics, University of Southern California, Los Angeles, CA, USA. ${ }^{2}$ School of Pharmaceutical Science and Technology, Tianjin University, Nankai District, Room 209, 24th building, 92th Weijin Road, Tianjin 300072, China. ${ }^{3}$ Center for Social Science Survey and Data, Tianjin University, Tianjin, China. ${ }^{4}$ School of Public Health (Shenzhen), Sun Yat-Sen University, Shenzhen, Guangdong, China.

Received: 11 March 2021 Accepted: 13 May 2021

Published online: 24 May 2021

\section{References}

1. Rogers S, Mclntosh RL, Cheung N, Lim L, Wang JJ, Mitchell P, Kowalski JW, Nguyen $\mathrm{H}$, Wong TY, International Eye Disease $\mathrm{C}$. The prevalence of retinal vein occlusion: pooled data from population studies from the United States, Europe, Asia, and Australia. Ophthalmology. 2010;117(2):313-319.e311.

2. Glanville J, Patterson J, McCool R, Ferreira A, Gairy K, Pearce I. Efficacy and safety of widely used treatments for macular oedema secondary to retinal vein occlusion: a systematic review. BMC Ophthalmol. 2014;14:7.

3. Evaluation of grid pattern photocoagulation for macular edema in central vein occlusion. The Central Vein Occlusion Study Group M report. Ophthalmology 1995;102(10):1425-1433.

4. Ip MS, Scott IU, VanVeldhuisen PC, Oden NL, Blodi BA, Fisher M, Singerman LJ, Tolentino M, Chan CK, Gonzalez VH, et al. A randomized trial comparing the efficacy and safety of intravitreal triamcinolone with observation to treat vision loss associated with macular edema secondary to central retinal vein occlusion: the Standard Care vs Corticosteroid for Retinal Vein Occlusion (SCORE) study report 5. Arch Ophthalmol. 2009;127(9):1101-14.

5. Chi G, Haskova Z, Chuo C, Chang S. Real-world treatment patterns for macular edema secondary to retinal vein occlusion in the United States. Invest Ophthalmol Vis Sci 2020;61.

6. Branch Vein Occlusion Study G. Argon laser photocoagulation for macular edema in branch vein occlusion. Am J Ophthalmol 2018;196:XXX-XXXviii.

7. Wei W, Weisberger A, Zhu L, Cheng Y, Liu C, Group BS. Efficacy and safety of ranibizumab in asian patients with branch retinal vein occlusion: results from the randomized BLOSSOM Study. Ophthalmology Retina. 2020;4(1):5766.

8. Ma Z, Zhu L, Weisberger A, Cheng Y, Liu C. Ranibizumab 0.5 mg in Asian patients with visual impairment due to macular edema secondary to central retinal vein occlusion: results from the 12-month CAMELLIA study. Invest Ophthalmol Vis Sci 2017;58(8):1543-1543.

9. Taylor M, Serbetci E, Ferreira A, Gairy K, Lewis L, Blouin J, Mitchell P. A United Kingdom-based economic evaluation of ranibizumab for patients with retinal vein occlusion (RVO). J Med Econ. 2014;17(6):423-34.

10. Regnier SA, Larsen M, Bezlyak V, Allen F. Comparative efficacy and safety of approved treatments for macular oedema secondary to branch retinal vein occlusion: a network meta-analysis. BMJ Open. 2015;5(6):e007527.

11. Klein $\mathrm{R}$, Klein BE, Linton $\mathrm{KL}$, De Mets DL. The Beaver Dam Eye Study: visual acuity. Ophthalmology. 1991:98(8):1310-5.

12. Brown GC. Vision and quality-of-life. Trans Am Ophthalmol Soc. 1999;97: 473-511.

13. Czoski-Murray C, Carlton J, Brazier J, Young T, Papo NL, Kang HK. Valuing condition-specific health states using simulation contact lenses. Value in Health. 2009;12(5):793-9.

14. WHO Global Health Observatory data repository Life tables by country China [EB/OL]. (2018-04-20) Available: http://apps.who.int/gho/data/view.ma in.60340?lang=en. Last Accessed 23 Jan 2020.

15. Cugati S, Cumming RG, Smith W, Burlutsky G, Mitchell P, Wang JJ. Visual impairment, age-related macular degeneration, cataract, and long-term mortality: the Blue Mountains Eye Study. Arch Ophthalmol. 2007:125(7):91724 
16. Cugati S, Wang JJ, Knudtson MD, Rochtchina E, Klein R, Klein BE, Wong TY, Mitchell P. Retinal vein occlusion and vascular mortality: pooled data analysis of 2 population-based cohorts. Ophthalmology. 2007;114(3):520-4.

17. Guan X, Lin F, Wang L, Ni Q, Shi L. Burden of low vision and blindness in Chinese elder popullation: data from field survey. Value in Health. 2016; 19(7):A565-6.

\section{Publisher's Note}

Springer Nature remains neutral with regard to jurisdictional claims in published maps and institutional affiliations.

Ready to submit your research? Choose BMC and benefit from:

- fast, convenient online submission

- thorough peer review by experienced researchers in your field

- rapid publication on acceptance

- support for research data, including large and complex data types

- gold Open Access which fosters wider collaboration and increased citations

- maximum visibility for your research: over $100 \mathrm{M}$ website views per year

At $\mathrm{BMC}$, research is always in progress.

Learn more biomedcentral.com/submissions 